\title{
The prevalence and implications of copy and paste: internal medicine program director perspectives
}

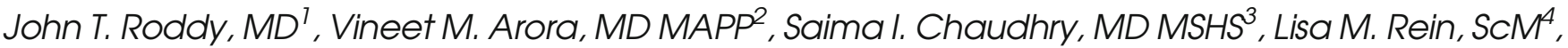 \\ Anjishnu Banerjee, PhD ${ }^{5}$, Sara L. Swenson, $M D^{6}$, and Kathlyn E. Fletcher, MD MA ${ }^{1,7}$ \\ 'Department of Internal Medicine, Medical College of Wisconsin, Milwaukee, WI, USA; ${ }^{2}$ Pritzker School of Medicine, University of Chicago, Chicago, \\ IL, USA; ${ }^{3}$ Memorial Healthcare System, Ft, Lauderdale, FL, USA; ${ }^{4}$ Institute for Health and Equity, Division of Biostatistics, Medical College of Wisconsin, \\ Milwaukee, WI, USA; ${ }^{5}$ Division of Biostatistics, Medical College of Wisconsin, Milwaukee, WI, USA; ${ }^{6}$ California Pacific Medical Center, San Francisco, \\ CA, USA; ${ }^{7}$ Milwaukee VAMC, Milwaukee, WI, USA.
}

KEY WORDS: Electronic health records; Graduate medical education; Patient safety.

J Gen Intern Med 33(12):2032-3

DOI: $10.1007 / \mathrm{s} 11606-018-4575-7$

(C) Society of General Internal Medicine (This is a U.S. government work and not under copyright protection in the U.S.; foreign copyright protection may apply) 2018

\section{INTRODUCTION}

Use of electronic health records (EHRs) is frequently accompanied by copying and pasting information from one note into another. ${ }^{1}$ Copy/paste can introduce inaccuracies and redundancy into notes which may have patient safety implications. Evidence for this assertion is based mainly on case reports, ${ }^{2}$ although one larger study implicated copy/paste as an occasional contributor to diagnostic errors. ${ }^{3}$ The use of copy and paste by resident physicians is a professionalism concern of the ACGME's Clinical Learning Environment Review. ${ }^{4}$ In this project, we aimed to determine internal medicine program directors' (PD) views of copy and paste in their programs.

\section{METHODS}

This was a national cross-sectional survey study conducted by the Association of Program Directors in Internal Medicine (APDIM). This annual survey of internal medicine PDs has sections that change each year; in fall 2013, one section was about electronic health records (EHRs), including copy/paste practices. Each program director that belongs to APDIM received an email with a unique link. Subsequent email and personal reminders were sent out to remind PDs to complete the survey. This Medical College of Wisconsin IRB considered this study to be exempt.
We report descriptive and univariate analyses. In univariate analyses, the outcome of interest was PD perception about how often quality and safety problems arose due to documentation inaccuracies from copy/paste. We dichotomized this variable as "very often" and "often" versus "sometimes," "rarely," and "never." Using Wilcoxon's rank sum tests, we looked at the relationship between PD perception of how often different parts of the note (history of present illness, physical examination, and assessment and plan) were copied/pasted and perceived quality and safety problems.

\section{RESULTS}

Of the 391 internal medicine program directors surveyed, 265 participated (response rate $=68 \%$ ). Most were communitybased and affiliated with a university $(51 \%)$ or universitybased $(37 \%)$. Nearly all $(97 \%)$ reported that their trainees used an EHR. The most commonly used EHRs were Epic (35\%) and Cerner $(25 \%)$. Less than half $(44 \%)$ of the programs had a specific policy on copy/paste; $32 \%$ reported working on a policy.

Of the 240 PDs that completed the survey section on copy and paste, $39 \%$ reported that residents often or very often copy/paste into their history of present illness sections, 39\% reported copy/paste in the physical examination section and $44 \%$ in the assessment and plan (Table 1). Nearly equal numbers reported that they "sometimes" copy/paste into those sections. The majority (69\%) agreed or strongly agreed that their residents receive feedback on their documentation, while $11 \%$ disagreed or strongly disagreed (20\% were neutral).

PDs reported commonly seeing documentation inaccuracies leading to negative effects on safety and quality because of copy/ paste (22\% reported that this happens often or very often, and another $44 \%$ reported that it happens sometimes). In univariate 
Table 1 Program directors' perception of frequency of copy and paste.

\begin{tabular}{llllll}
\hline \hline $\begin{array}{l}\text { Section } \\
\text { of note }\end{array}$ & \multicolumn{4}{l}{ Perceived frequency of copy and paste $\boldsymbol{N}(\%)$} \\
\cline { 2 - 6 } & Never & Rarely & Sometimes & Often & Very often \\
\hline HPI & $27(11)$ & $9(16)$ & $79(33)$ & $67(28)$ & $27(11)$ \\
PE & $30(13)$ & $29(12)$ & $85(36)$ & $65(27)$ & $28(12)$ \\
A/P & $22(9)$ & $33(14)$ & $76(32)$ & $74(32)$ & $30(13)$ \\
\hline
\end{tabular}

HPI history of present illness, PE physical examination, A/P assessment and plan

analyses, PDs reporting that copy/paste had a negative impact on safety and quality was more likely to note copy/paste in the HPI $(p<0.01)$, physical exam $(p<0.01)$, and assessment/plan $(p<0.01)$ (Fig. 1). There was no association between PDs reporting that copy and paste had a negative impact and being at a community versus a university program; region of the country was also not significantly associated with this perception.

\section{DISCUSSION}

In 2009, only a quarter of respondents felt that notes with copied and pasted information were more likely to lead to

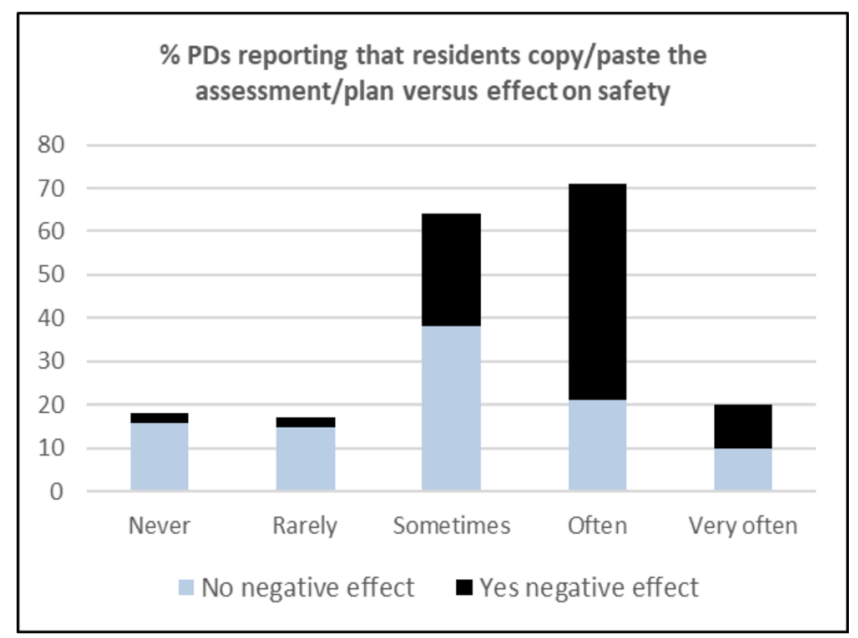

Figure 1 Percentage of program directors reporting that residents copy and paste versus the perceived effects on safety. patient care mistakes. ${ }^{1}$ Our data suggest that at least among PDs, that number is much higher. In addition, not all programs have clear EHR documentation policies. Limitations of our study include that this was a survey of PDs and not residents. PDs may not witness all cases of copy/paste (which may underestimate concerns regarding rates of usage and potential harms). Given the widespread use of EHRs, it seems prudent to have documentation policies in place to guide practice. Others have suggested providing education about copy/paste and monitoring its use. ${ }^{5}$ More drastic measures for curbing copy/paste might include turning off copy/paste functionality altogether. However, any efforts to do so should be studied with attention to balancing measures such as decreased efficiency in note writing. Sharing best practices for teaching and monitoring high-quality EHR documentation practices would also be useful to the education community.

Acknowledgements: This work was done in collaboration with the Association of Program Directors in Internal Medicine Survey Committee.

Corresponding Author: Kathlyn E. Fletcher, MD MA; Department of Internal MedicineMedical College of Wisconsin, Milwaukee, WI, USA (e-mail: kfletche@mcw.edu).

\section{Compliance with Ethical Standards:}

Conflict of Interest: The authors declare that they do not have a conflict of interest.

\section{REFERENCES}

1. O'Donnell HC, Kaushal R, Barron Y, Callahan MA, Adelman RD, Siegler EL. Physicians' attitudes towards copy and pasting in electronic note writing. J Gen Intern Med. 2009;24(1):63-68.

2. Hersh W. Cases \& commentaries: Copy and paste Web M\&M 2007; http://webmm.ahrq.gov/printviewCase.aspx?caseID=157. Accessed 8 February, 2018.

3. Singh H, Giardina TD, Meyer AND, Forjuoh SN, Reis MD, Thomas EJ. Types and origins of diagnostic errors in primary care settings. JAMA Intern Med. 2013;173(6):418-425.

4. Wagner $\mathbf{R}, \mathbf{K o h}, \mathbf{N}$, Bagian, JP, Weiss, KB, for the CLER Program. CLER 2016 National Report of Findings. Issue Brief \#8: Professionalism. 2017; https://www.acgme.org/Portals/0/PDFs/CLER/ACGME_CLER_Issue Brief_Professionalism.pdf. Accessed 8 February 2018.

5. Tsou AY, Lehmann CU, Michel J, Solomon R, Possanza L, Gandhi T. Safe practices for copy and paste in the EHR. Systematic review, recommendations, and novel model for health IT collaboration. Appl Clin Inform. 2017;8(1):12-34. 